\title{
Arte y moda: ¿fusión o encuentro? Reflexiones filosóficas
}

Roberto E. Aras *

\begin{abstract}
Resumen: La moda se encuentra con el arte como expresión de una densidad estética que muchas veces la inspira y atraviesa. Sin embargo, el arte de hoy no sólo es una influencia sustantiva para la moda sino que, muchas veces, se fusiona con aquel en una desesperada búsqueda de nuevos escenarios de seducción y de venta. En este sentido, moda y museo parecen tener dinámicas concordantes. Por otra parte, la evolución de las industrias culturales condiciona los modos de relación entre arte y moda, y cuestiona a la belleza como la categoría fundamental para el encuentro.
\end{abstract}

Palabras clave: arte - belleza - código - estética - moda - museo - seducción.

[Resúmenes en italiano, inglés y portugués en las páginas 69-70]

${ }^{(*)}$ Doctor en Filosofía (Universidad de Navarra, 2004). Licenciado en Filosofía (UCA, 1987). Profesor Titular Ordinario en la Pontificia Universidad Católica Argentina en el Instituto de Ciencias Políticas (ICPRI) y en el Instituto de Comunicación Social (ICOS). Secretario Académico de la Facultad de Ciencias Sociales, Políticas y de la Comunicación de la Universidad Católica Argentina.

Georg Simmel ${ }^{1}$ nos advierte, ya al comienzo del siglo pasado, que la moda suministra la clave para examinar una época. Sus variaciones funcionan como una brújula para anticipar tendencias sociales, económicas o, incluso, políticas. Sin embargo, si desde la perspectiva de su diseño y contenido la moda se encuentra con el arte como expresión de una densidad estética que muchas veces la inspira y atraviesa, desde su estructura formal, la moda ocupa el lugar de un símbolo que comunica las aspiraciones sociales y provee la identidad de grupo que sostiene las conductas individuales.

En este punto, los cambios en la moda implican la movilidad oculta de las interacciones humanas y por eso, como lo observaba Veblen, adquiere una dimensión transaccional -económicaque pone en cuestión su valor funcional. ¿Es el arte, hoy, una fuente de inspiración e influencia para la moda, o es la moda quien, bajo la meta-exigencia de la mutación permanente, se funde con el arte en una desesperada búsqueda de nuevos escenarios de seducción y de venta? ¿Cuáles son los límites -si los hay- para salvar la originalidad de la moda y, al mismo tiempo, purificar al arte de sus expresiones más efímeras? ¿La evolución de las industrias culturales y creativas condiciona los modos de relación entre arte y moda? 
Estas son algunas de las preguntas que guiarán el derrotero de las próximas páginas, escritas como un ejercicio que intenta comprender las nuevas circunstancias que regulan la relación entre el arte y la moda actuales.

\section{Las condiciones del encuentro}

Uno de los aspectos sobresalientes en el análisis de la moda y que ocupa el centro de la atención de los investigadores es el dinamismo en los cambios que ella impone y la permanente mutación, a escala histórica, de los criterios con los cuales se juzgan sus productos. Hacia el final del siglo XIX, el sociólogo norteamericano Thorstein Veblen se lamentaba de que aquella "lucha incesante para conseguir la belleza en el vestir" no resultara en "una aproximación gradual a la perfección artística". Sólo así -pensaba- se confirmaría una relativa estabilidad en sus realizaciones en orden a consagrar un ideal artístico que mantuviera la tendencia constante en las formas que visten al ser humano. De esta manera, asociaba la insatisfacción declarada en la sucesión continua de las modas con la falta de un paradigma universal que acordase, al modo como lo hace el arte, un período de consensos más o menos prolongado.

Algunos años después, Helen Grund también se quejaba de que "el cambio continuo de la moda, que decreta una revisión constante de todas las partes de la figura, obliga a la mujer a preocuparse permanentemente de la belleza" 2 .

Según las declaraciones citadas, parece que la primera coincidencia entre arte y moda se revela en las pretensiones, que ambos comparten, de concretar una obra "bella", aunque la variación en la moda haga difícil identificar un ideal que cumpla con la función canónica que en el arte ocupan las "escuelas" o los "movimientos". Se trata, entonces, de una convergencia accidentada, no exenta de conflictos, que no puede ignorar los matices que señala la propia historia de la estética pero tampoco admitir una separación quirúrgica, precisamente en un terreno en el que se expresa la misma espiritualidad humana ${ }^{3}$.

Por ello interesa recordar que, si Aristóteles reservaba el adjetivo "bello" para lo dotado de "magnitud y orden", mientras Santo Tomás prefería definirlo como "aquello que a la vista place" -concepto fundado en la proporción y la armonía-, la filosofía moderna se inclinó por establecer que la belleza artística procedía de la subjetividad del gusto y de la universalidad del juicio estético (Kant), los cuales marcan el nivel de su valoración ${ }^{4}$. El lugar para la crítica de la belleza era, entonces, el individuo y el fenómeno de la apreciación artística sólo podía ser tratado dentro de los límites de la psicología. En la moda, por otra parte, la belleza aparecía como el resultado de un arte "menor" -o simplemente una "técnica"- logrado por la combinación adecuada del diseño, la nobleza de los materiales y la paleta de colores o texturas, siempre que dichos factores se encontraran aceptados por la sensibilidad general de la época. Se comprende, pues, por qué la belleza en la moda se manifestara siempre vinculada con otras exigencias que proceden tanto del reconocimiento social -que reúne la capacidad para nuclear, distinguir y elevar-, como de la funcionalidad con que la vestimenta permite cumplir las tareas de la vida cotidiana o acomodarse a las exigencias de un traje gremial -la capacidad para identificar-.

Estas razones nos llevan a ejecutar una distinción entre las diversas dimensiones del vestido humano que no se agotan en la "estética", en tanto preocupación por la belleza, sino que se amplían con las funciones "higiénica", "púdica" y "distintiva"5; de ellas, sólo la última conduce 
a una consideración claramente social del fenómeno del atuendo. $Y$ es a partir de esa mirada de la moda como un hecho intrínsecamente semiótico o comunicativo que se inscribe en un ámbito de relación con otros múltiples factores de transacción social como, por ejemplo, el dinero o la reputación. De ahí que Veblen haya imaginado una ley de proporcionalidad inversa por la cual el aumento de la riqueza y el derroche ostensible (con el consiguiente crecimiento de la reputación pecuniaria) son suficientes para provocar el abandono o la superación del sentido de la belleza. La consecuencia inmediata es que la rotación de las modas se acelera y el criterio estético pierde paulatinamente su peso decisorio. La sociología, entonces, desplaza a la psicología de la estética y se hace cargo de la interpretación de la moda.

De modo que, habiendo identificado al comienzo una región de encuentro en torno al ideal de "belleza", sin embargo, pronto hemos advertido que el gusto y la apreciación estética no son suficientes para una demarcación significativa en el territorio de los intercambios entre arte y moda, y debemos recurrir a una inspección más sofisticada de las condiciones del "exhibirse" como clave hermenéutica para desentrañar el nuevo constructo cultural del arte-moda.

\section{La tentación de la fusión}

En su famoso estudio "La obra de arte en la época de su reproductibilidad técnica", Walter Benjamin introduce la idea de aura con la intención de explicar qué es lo que se pierde en la multiplicación de una pieza original ${ }^{6}$. La singularidad y la irrepetibilidad otorgan una dimensión única a aquellas cosas que se inscriben en el ámbito de la creación artística. La reproducción y la masividad facilitan el acceso a la apropiación del arte pero, al mismo tiempo, eliminan la autenticidad que es la nota que remite a la historicidad del origen.

La vinculación, pues, entre el aura y la autenticidad se establece al modo de una pausa en el flujo temporal que sustrae al arte del devenir y lo mantiene a salvo de la valoración circunstancial. La denominada eternidad del arte, es decir, el reconocimiento de la perfección sin límites de espacio o tiempo, resguarda su esencia de la contaminación dialéctica a la que se vería sometido en los escenarios cambiantes de la galería, el teatro o la sala musical. Cuando el arte eterno -y por eso, lejano- pierde el aura, se convierte en objeto inmediato, consumible, mero residuo icónico más apto para la crítica que para la fruición ${ }^{7}$, desmontado de todo aparato ritual y, finalmente, nostálgico de su abandonada condición trascendente.

Un aspecto crucial de este proceso ha sido tratado por Jean Baudrillard cuando advierte que "la exigencia museal de inscripción eterna de las formas y la de la actualidad pura funcionan simultáneamente en nuestra cultura” (Baudrillard, 1980, p. 103), porque son el resultado de la reducción al mínimo cultural simbólico, matriz de nivelación y reutilización universal. Esta equiparación logra eliminar, precisamente, las marcas temporales del aura y extiende la permutación de las formas artísticas al infinito. De ahí que, según Baudrillard, el museo y la moda hayan surgido contemporáneamente:

La moda hace lo mismo según su ciclo: conmuta y hace jugar entre sí a todos los signos absolutamente. La temporalidad de las obras de museo es la del perfecto, de la perfección: es el estado muy particular de lo que ha sido, y jamás actual. Pero la moda tampoco es jamás actual: especula con la competencia de 
las formas a partir de su muerte y de su almacenamiento, como signos, en una reserva intemporal. La moda readapta de un año al otro lo que ha sido, con una libertad combinatoria enorme. De ahí también su efecto de perfección instantánea. Perfección museal también, pero de formas efímeras (Baudrillard, 1980).

Si ahora seguimos esta línea de razonamiento no nos sorprenderá encontrar, cada vez más, experiencias de fusión de moda y museo, que respondan a la doble necesidad cultural de la «nivelación semiótica»-como garantía de coexistencia de lo diferente-, por una parte, y de «novedad»-como oposición a la tradición de estilos incompatibles o apariencias contradictorias-, por otra. Así, el arte se abre, gracias a la plataforma de legitimación que es el museo, para recibir expresiones de la moda que buscan su identidad generando una fusión entre ambos universos, pero también subordinándose al proceso de desacralización que implica el estadio final de la democratización de la moda ${ }^{8}$.

Para mencionar sólo algunos casos de aquella tendencia, basta recordar que el diseñador valenciano Manuel Fernández inauguró el 9 de septiembre de 2011 en el Museo Príncipe Felipe de La Ciudad de las Artes y de las Ciencias de Valencia una muestra que fusiona sus trajes con las pinturas de artistas como Chillida, Úrculo, Genovés, Manolo Valdéz o Viteri. El proyecto recibió el título de Fashion Art y ya en el año 2003 se había iniciado con una primera exposición en el Museo de Bellas Artes de Buenos Aires. Y es en esa misma ciudad, en el marco de la mayor muestra de arte, ArteBA -edición 2010-, que Tramando de Martín Churba presentó un ejemplo de art-couture al invitar a la artista Paula Toto Blake a diseñar piezas en goma negra bajo el título de "Sombras", que serían emuladas por los textiles de la casa de modas.

Con intención similar, la sevillana Carla Corcías propone, desde el año 2000, piezas de moda pintadas a mano por ella con el objetivo de darles exclusividad. "Arte en la moda" -sostiene- es su objetivo y con esa consigna elabora vestidos, camisetas, carteras, collares y otras prendas decoradas por su mano.

La colección otoño-invierno 2010/2011 de las diseñadoras colombianas Trinidad Castillo y Carmen Schäfer se presentó en el marco de la exposición de la Colección Norte de Arte Contemporáneo, ubicada en el vestíbulo de la Biblioteca Central de Cantabria, bajo el nombre de Ariadne y el Minotauro, de manera que los visitantes debían adentrarse, metafóricamente, entre los cuadros de la muestra como en un laberinto para descubrir las creaciones de las autoras. Algo similar ocurre en Londres desde 1999, en el Albert \& Victoria Museum, donde se desarrolla el evento mensual Moda en Movimiento que "cruza el puente entre las pasarelas en vivo y las muestras estáticas del museo. Transmitiendo la energía de la moda como acción, las modelos caminan por las galerías del museo usando las últimas colecciones de los máximos diseñadores" (Anderson, 2005, p. 377).

Finalmente, otro ejemplo lo constituye la exposición del museo del Fashion Institute of Techno$\log y$ (FIT) de Nueva York, que inauguró en diciembre de 2011 "Grandes diseñadores: parte uno", donde se exhiben obras de destacados modistas de los siglos XX y XXI como Christian Dior o Coco Chanel. Entre las obras expuestas se destaca un traje de chaqueta estampado con cuadros de Marilyn Monroe pintados por Andy Warhol, simbolizando la fusión entre moda y arte.

Ha quedado claro, por la enumeración anterior, que la moda - una vez sometida esencialmente a la reproductibilidad técnica-, pretende recibir el aura de la originalidad -y de la permanencia-cuando es validada por el arte. Conste que aquí no nos referimos a los cruces o influencias 
que ha recibido la moda por parte del arte y que, a lo largo de la historia, reconoce algunos paradigmas magistrales9. En este punto, cabe recordar que "en 1927 Sonia Delaunay daba una conferencia en La Sorbona titulada "La influencia de la Pintura en el Arte del Vestido", organizada por el Grupo de Estudios Filosóficos y Científicos, donde equipara los cambios en la pintura desde el Impresionismo a los cambios en el vestido, habló de geometría, color y de una concepción de los vestidos con criterios artísticos"(Capilla, 2003). Entre nosotros, es conocida la muestra de la artista -vinculada con el Instituto Di Tella- Dalila Puzzovio, "Doble Plataforma”, en la década del ' 60 en la que se exponían zapatos diseñados por ella10.

No, en rigor, aquí hablamos de una transfiguración de la moda que la lleva al límite de su función social. Como afirma Lipovetsky, se hace necesaria una nueva substancialización casi de raíces ontológicas -para el hombre tanto como para sus creaciones-, un nuevo peso significativo, que sea capaz de superar la obsolescencia acelerada (Lipovetsky, 1990, p. 107) distintiva de la lógica de la moda. Y es ella misma la que recurre al expediente de la fusión como salvaguarda final para su vigencia, porque sabe del riesgo que significa la permutación de la copia por el original y la entronización de la simulación ${ }^{11}$.

La ecuación de la moda-arte ofrece, entonces, la ilusión de derrotar la dinámica de la sociedad de consumo y sus procesos cíclicos de producción de valores-signo ${ }^{12}$ a favor de un ideal de consistencia y perdurabilidad.

\section{Sobre códigos, apariencias y simulaciones}

Cuando R. Barthes, ya en 1967, interpreta que la moda se asemeja a un lenguaje ${ }^{13}$ con su propia gramática -el código de la moda ${ }^{14}$ - no sólo nos ofrece un camino de exploración hacia la constitución de su núcleo íntimo sino que nos anima a someter a una adecuada contextualización cada intento por decodificarla. En efecto, "con la moda, la superficie corporal se convierte en el locus simbólico a partir del cual se pone en marcha el lenguaje de las relaciones sociales" (Vidal Claramonte, 2003, p. 86). Esta dimensión comunicativa ${ }^{15}$-esto es, fundamentalmente, relacional- esconde, sin embargo, una diferencia radical respecto de su capacidad referencial. Baudrillard lo explica así:

La moda, como el lenguaje, apunta en el acto a la socialidad (el dandy, en su soledad provocadora, es la prueba de ello a la inversa). Pero a diferencia del lenguaje, que apunta al sentido y se esfuma ante él, la moda apunta a una socialidad teatral, y se complace en sí misma. (...) Contrariamente al lenguaje que apunta a la comunicación, ella simula la comunicación, hace de ella la puesta sin fin de una significación sin mensaje. De ahí su placer estético que nada tiene que ver con la belleza o la fealdad (Baudrillard, 1980, pp. 108-109).

El pensador francés nos advierte sobre algo que todavía no habíamos observado. Ya no se trata de superar el ideal de belleza -punto de contacto posible con el arte- sino de establecer que lo estético constituye un límite en sí mismo, un estadio narcisista en el cual el mensaje se vuelve sobre el sujeto en un juego de espejos ${ }^{16}$ que construye una representación de sí mismo ${ }^{17}$, psicológica, social y comunicativa, para consumo personal. Asoma, pues, una «estética de la 
identidad» en la que "el hablante del lenguaje de la moda es un creador de información nueva, inesperada para el público e incomprensible para éste" (Lotman, 1999, p. 56). porque el primer destinatario es él, en tanto observador privilegiado de su propia autoconstitución ${ }^{18}$.

Ahora bien, esta perspectiva reclama una revisión del nexo semiótico entre arte y moda. Si antes habíamos justificado la aproximación entre ellos como un intento de la moda por conseguir la transferencia del aura artística y así lograr cierta dislocación de los ciclos programados de obsolescencia, ahora nos enfrentamos al vaciamiento de la representación -susceptible del arco de valoraciones que van desde la belleza a la fealdad-causado por la auto-referencialidad del sujeto de la moda. ¿Qué diferencia al dandy decimonónico y a su afán de no ser aceptado (e imitado) por los demás, de este nuevo «solitario» devenido protagonista de una humanidad artificial, fantasmagórica? 19

La búsqueda de una imagen corporal de sí mismo adquiere hoy la plasticidad del arte que se ejecuta sobre el lienzo blanco o sobre el mármol sin forma ${ }^{20}$. La indumentaria es tan sólo uno de los factores que facilitan una replicación constante de los rasgos más deseables de nuestra biografía: la juventud, la sexualidad, el ánimo o la actitud pueden ser «fijados» con ayuda de la moda. Las máscaras multiformes del mundo fashion son la llave de la permanencia o del cambio en la apariencia; es el éxtasis de la simulación que gratifica pero que no logra articularse en los vínculos sociales y sepulta al individuo bajo el peso de un aislamiento frágil e ingenuo. La «precesión del simulacro» de la moda -como lo llamaría Baudrillard-implica "la transición desde unos signos que disimulan algo a unos signos que disimulan que no hay nada" (Baudrillard, 1987 a, p. 18).

Por eso, quizás, las experiencias de moda-arte, en clave de fusión, intentan ser la última carta para conseguir una lectura abierta de la vestimenta que remita a un observador autónomo capaz de "estilizar y aprisionar en una expresión significativa el furor pasajero de los cuerpos o el remolino infinito de las actitudes" (Camus, 2008, p. 333).

\section{¿Hacia una moda trans-estética o meta-estética?}

Las ideas y pensamientos que hemos recorrido durante este artículo en torno al encuentro y la fusión entre el arte y la moda, nos llevan a plantear una última cuestión que hoy se presenta en el horizonte de las reflexiones sobre el futuro del diseño y la producción de indumentaria. Hasta aquí vimos cómo las funciones estética y social de la moda se asociaban o modificaban generando diversas alternativas para la comprensión de este fenómeno. Sin embargo, en todos los casos, la consideración estética -en un sentido amplio- validaba los excesos artesanales de las prendas y justificaba la necesidad de cierta permanencia en la variación. Pero, es lícito interrogarse, qué sucedería si este factor que atraviesa la historia del vestido $-y$, por ello, podría denominarse trans-estético- fuera removido de todas las expresiones de la moda. ¿Es absurdo, acaso, pensar en una moda reglamentada por la función utilitaria (higiénica, púdica y, hasta cierto punto, social) como parecían imaginar los autores de ciencia ficción al aventurarse a describir los usos y costumbres de nuestro planeta en los próximos siglos, o incluso las incursiones de habitantes extraterrestres? Atendiendo a la búsqueda de la supresión de las diferencias en las ropas -que intentaron varias utopías políticas del siglo pasado- para consolidar ciertas formas del trabajo y de la convivencia social, ¿ha sido superada total y definitivamente la voluntad de 
uniformizar gracias a la posibilidad de complacer las demandas que surgen de una fragmentación microscópica que la sociedad de la información ha podido ejecutar sobre los intereses del mercado? En esas condiciones ¿podrá seguir anidando en el núcleo de la moda su carácter unitivo, estructurante, que había visto tan bien Simmel?

Una respuesta clarificadora de esos interrogantes exigiría mucho más espacio del que es posible disponer en estas páginas pero, al menos, quede apuntado que algunos ya comienzan a hablar de una moda «transhumanista» en la cual el sueño de una extensión del cuerpo y del vestido hacia los objetos circundantes o el manejo de dispositivos tecnológicos bio-articulados, empieza a tener una fecha de aparición. La combinación de los aportes de la nanotecnología con telas «inteligentes», piel digital o venas «iluminadas», para citar sólo algunos ejemplos de otras muchas anticipaciones, abrirían una época meta-estética en la cual la moda estaría perfectamente integrada con nuestras necesidades vitales -las de todos, y por ende, sin diferencias ni lugar para excepciones.

¿Seguirán siendo «moda» estos recursos indumentarios o habremos alcanzado finalmente un estado de perfecta anulación de las fronteras estéticas y sociales? El desafío del mantenimiento de la moda como «principio de realidad» para auscultar las tendencias y los ritmos sociales podría resultar en un fracaso, y entonces se verificaría el atroz destino ${ }^{21}$ que Baudrillard profetizaba para la sociedad en una gran implosión final. Pero si sucede, esa reversión ocurrirá en el plano de la intimidad y no en el ágora pública; será la decadencia suave hacia la que nos conduce irremediablemente la «seducción», instalada en la óptica de todos los acontecimientos:

La seducción es aquello que no tiene representación posible, porque la distancia entre lo real y su doble, la distorsión entre el Mismo y el Otro está abolida. Inclinado sobre su manantial, Narciso apaga su sed: su imagen ya no es «otra», es su propia superficie quien lo absorbe, quien lo seduce, de tal modo que sólo puede acercarse sin pasar nunca más allá, pues ya no hay más allá como tampoco hay distancia reflexiva entre Narciso y su imagen. El espejo de agua no es una superficie de reflexión, sino una superficie de absorción (Baudrillard, 1987 b, p. 67).

La moda-arte, posiblemente "deberá rendirse a la orgía de la tolerancia, al sincretismo total, al absoluto e imparable politeísmo de la belleza” (Eco, 2004, p. 428), pero también nos concederá la oportunidad privilegiada de ensayar una salida, de planificar una salvífica evasión hacia los territorios de la verdad y la belleza.

\section{Notas}

1. Cfr. Simmel (1938), especialmente pp. 133-172.

2. Sobre la esencia de la moda, Munich 1935, pp. 7-8 (citado en Benjamin (2005), p. 101)

3. Cfr. Veblen (1974), p. 174: "La necesidad del vestido es una necesidad eminentemente espiritual o superior".

4. Todavía en 1747, Charles Batteaux definiendo la belleza repetía: "La teoría general de la belleza que se formuló en tiempos antiguos afirmaba que la belleza consiste en las proporciones 
de las partes, para ser más precisos, en las proporciones y en el ordenamiento de las partes y en sus interrelaciones" (citado en Fernández Uribe, 2008, p. 110)

5. Cfr. Gablot (2004), citado en Revista de Occidente (2011), pp. 89-90.

6. Cfr. Benjamin (2011), p. 100: "en la época de la reproducción técnica de la obra de arte lo que se atrofia es el aura de ésta".

7. Cfr. Lipovetsky (1986, p. 98): "Indiscutiblemente puede verse el eclipse de la distancia como una de las aspiraciones del arte moderno, a condición de no ocular su efecto estrictamente inverso, su carácter hermético, «intelectualista», «intransigente», decía Adorno. Resulta demasiado simplista tomar en consideración únicamente las intenciones de los artistas, igualmente significativa es la acogida de estas obras que, hoy como ayer, perturban profundamente el proceso de comunicación y dejan al público perplejo. Cómo hablar de eclipse de la distancia respecto de obras cuyas construcciones insólitas, abstractas o dislocadas, disonantes o mínimas han provocado el escándalo, confunden la evidencia de la comunicación, perturban el orden de la continuidad espacio-temporal y conducen por ello al espectador no tanto a recibir emocionalmente la obra como a interrogarle de forma crítica."

8. Cfr. Lipovetsky (1990, p. 135): "Desde el momento en que se eclipsa el imperativo de la indumentaria dispendiosa, todas las formas, todos los estilos y todos los materiales cobran legitimidad como moda: el desaliño, lo sucio, lo desgarrado, lo descosido, lo descuidado, lo usado, lo deshilachado, hasta el momento estrictamente excluidos, se incorporan al campo de la moda. $\mathrm{Al}$ reciclar los signos «inferiores», la moda prosigue su dinámica democrática, tal y como lo han hecho, desde mediados del siglo XIX, el arte moderno y las vanguardias."

9. Cfr. Vidal Claramonte (2003, p. 91): "En este sentido, cabe destacar el hecho de que los diseñadores se fijen muchas veces en los discursos pictóricos: es muy conocida la relación entre Chanel y Jean Cocteau, entre Schiaparelli y Dalí, entre Poiret y Diaghilev, o las incursiones de la pintora Sonia Delauney en el mundo de la moda, cuando diseñó vestidos en la década de los años veinte y treinta del siglo XX influida por el cubismo de Picasso o Gris. Por su parte, Balenciaga se inspira en Velazquez o Zurbarán, Saint Laurent en Mondrian, Warhol, Picasso o Van Gogh; y Armani en Kandinsky y Matisse." En la exposición ArteBA 2012 también aparecen estas duplas creativas de moda y arte: Nora Aslan y Martín Churba, Garza Lobos y Lorena Ventimiglia, Cora Groppo y Fabiana Barreda, Vicki Otero y Rocio Coppola, etc. (Cfr. La Nación Revista, 26 de febrero de 2012, pp. 32-35).

10. Otro tanto podría decirse de Delia Cancela y su marido Pablo Mesejenan, cuya primera colección de ropa fue comprada por el Victoria \& Albert Museum (Cfr. La Nación Revista, 26 de febrero de 2012, p. 29).

11. Es interesante releer, a la luz de lo dicho, el siguiente texto de M. Horkheimer y T. Adorno (1979): "En lugar de exponerse a este fracaso, en el que el estilo de la gran obra de arte se ha visto siempre negado, la obra mediocre he preferido siempre semejarse a las otras, se ha concretado con el sustituto de la identidad. La industria cultural, en suma, absolutiza la imitación" (p. 189).

12. Cfr. Martínez Barreiro (1996), p. 102.

13. Cfr. Lurie (1994, p. 22): "Si la indumentaria es una lengua, debe tener un vocabulario y una gramática como ocurre con el resto de las lenguas. Por supuesto, como ocurre con el habla humana, no hay una sola lengua de la indumentaria sino muchas: unas (como el holandés y el 
alemán) muy relacionadas entre sí y otras (como el vasco), casi únicas. Y dentro de cada lengua de la indumentaria hay muchos dialectos y acentos distintos. Por otra parte, como ocurre con el habla, cada individuo tiene su propio repertorio de palabras y emplea variaciones personales de tono y significado." Para entender mejor esta posición teórica respecto de la moda, cfr. Joanne Entwistle (2002), p. 80: "La naturaleza lingüística de la moda y el vestir es tenida en cuenta por teóricos como Davis (1992), Polhemus y Proctor (1978) y Rouse (1989), pero llevada a extremos en la obra de Lurie (1981). Ella sugiere que la moda tiene una "gramática» y un «vocabulario» como los lenguajes hablados, lo que hace que el vestir teóricamente sea más amplio que el lenguaje oral, incluyendo el peinado, la postura corporal, la forma de andar, etc." 14. Cfr. Barthes (2003), p. 419: "El vestido se percibía como una especie de lengua, de gramática: el código de la vestimenta. Comprobamos así que el vestido participa de esa actividad tan vital consistente en conferir un sentido a los objetos. Desde siempre, el vestido ha sido objeto de codificación".

15. Cfr. Quintas Froufe (2010), p. 200 y sgts.

16. Cfr. Camus (2008), p. 71: "El petimetre* crea su propia unidad por medios estéticos. Pero es una estética de la singularidad y la negación. «Vivir y morir ante un espejo»; tal era, según Baudelaire, la divisa del petimetre.” [ ${ }^{\star}$ elegante]

17. En el dandi, el arte y la moda forman parte de un mismo proyecto de construcción y representación de sí mismo. Cfr. Schiffer (2009), p. 160: "Hemos llegado pues por fin al corazón mismo del sujeto mismo que nos preocupa: ¡la estetización, en el dandi, de su propia persona por un constante trabajo sobre sí mismo!

Ya que lo que, en un primer tiempo, acerca el dandi al artista, es primero sin duda, más allá de su gusto innato por la transgresión o su ostentosa preocupación por sorprender, su sentido estético, en tanto lo que los aleja, a la inversa, en un segundo momento, es que, en el dandi, ese sentido estético no se aplica más, como para el artista, a la creación de una obra de arte (sea literaria, musical, pictórica, arquitectónica o plástica) exterior a él mismo, sino más bien a la construcción, de manera también artística, de su propia persona."

18. Cfr. Stefanini Zavallo (2012, p. 199): "El cuerpo pasó de ser límite a transformarse en materia creativa: el cuerpo como potencia que pone en acto nuestros más profundos anhelos. Nada es estático, ni la forma, ni el color, puedo estirar, encoger, alargar, quitar o poner y luego dar marcha atrás y volver a empezar, si es que los criterios del ideal femenino cambian nuevamente o plantean nuevas formas a imitar.

La revista Vogue vió claramente este proceso y bajo la guía de Ana Wintour fue una de las primeras publicaciones en tratar la belleza femenina como creación. La conducción de Ana Wintour generó un cambio en el enfoque de la revista que dio paso del culto de la belleza a la creación de la belleza."

19. Cfr. Benjamin (2005, p. 107): "Focillon sobre la fantasmagoría de la moda: «La mayoría de las veces... crea... híbridos, impone al ser humano el perfil de la bestia... La moda inventa así una humanidad artificial que no es la decoración pasiva del medio formal, sino ese medio mismo. Esta humanidad alternativamente heráldica, teatral, mágica, arquitectónica, tiene ... como regla... la poética del ornamento, y lo que llama línea ... quizá no sea sino un sutil compromiso entre cierto canon fisiológico... y la fantasía de las figuras». Henri Focillon, Vie des formes [Vida de las formas]. París, 1934, p. 41. [B9 a, 2].” 
20. Cfr. Kaczan (2009, p. 25): "Verdaderamente hace falta que el cuerpo de la mujer sea maleable y flexible como barro para que él se acomode a los caprichos de nuestras modas, señala Le Grand Prix"*.

El discurso revela, en tono de imposición, el grado de influencia de la moda sobre el cuerpo, como si él pudiera construirse eludiendo su estructura ósea y muscular. Y esta idea se fortalece al ser vivificada en la imagen del barro como materia manipulable. Para alcanzar tal fin, es necesario que el cuerpo se modifique, que atestigüe la mimesis con los patrones impuestos."

[* Blanc, Charles, "Considérations sur le vêtement des femmes". Institut de France. 25 oct 1872, p 12, citado en Croci, Paula - Alejandra Vitales (Comp.), (2000), Los cuerpos dóciles, Buenos Aires: La marca, p. 39.]

21. Baudrillard (1993), p. 170: “... habría que incluir en el mismo orden de figuras la precesión de los modelos sobre lo real, donde se resume nuestro «destino» moderno, el de la simulación, donde cabe interpretar en efecto una forma de catástrofe de la realidad, ese vértigo del modelo, de lo virtual y de la simulación arrastrándonos cada vez más lejos de las condiciones iniciales del mundo real".

\section{Referencias Bibliográficas}

Anderson, F. (2005). "Museums as Fashion Media", en Bruzzi, S. y Church Gibson, P. (Ed.), Fashion Cultures -theories, explorations and analysis. New York: Routledge.

Baudrillard, J. (1993). La ilusión del fin. Barcelona: Anagrama.

(1987 a). Cultura y Simulacro. Barcelona: Kairós.

(1987 b). De la seducción. Madrid: Cátedra.

(1980). El intercambio simbólico y la muerte. Caracas: Monte Ávila.

Barthes, R. (2003). El sistema de la moda y otros escritos. Barcelona: Paidós.

Benjamin, W. (2011), Conceptos de Filosofía de la Historia, Buenos Aires: Agebe.

(2005). Libro de los Pasajes. Madrid: Akal.

Camus, A. (2008). El hombre rebelde. Buenos Aires: Losada.

Capilla, S. (2003). El siglo XX: entre el traje y la moda, en Textil e indumentaria [Recurso electrónico]: materias, técnicas y evolución. 31 de marzo al 3 de abril de 2003, Facultad de Geografía e Historia de la U.C.M., págs. 231-244. Consultado el 24/02/2012 en http://ge-iic.com/ files/Publicaciones/el_siglo_XX.pdf

Consultado el 24/02/2012 en http://ge-iic.com/files/Publicaciones/el_siglo_XX.pdf

Celant, G. (2008). Artmix: Flussi tra arte, architettura, design, moda, musica e televisiones. Milano: Feltrinelli.

Eco, U. (2004). Historia de la Belleza. Barcelona: Lumen.

Entwisle, J. E. (2002). El cuerpo y la moda. Una visión sociológica. Barcelona: Paidós.

Fernández Uribe, C. A. (2008). Concepto de arte e idea de progreso en la Historia del Arte. Medellín: Universidad de Antioquia.

Gablot, E. (2004). La barrera y el nivel. Madrid: CIS.

Horkheimer, M.; Adorno, T. (1979). Industria cultural y sociedad de masas. Caracas: Monte Ávila Ed. 
Kaczan, G. P. (2009). Los modos de parecer de los cuerpos femeninos en los primeros años del siglo XX. Simulaciones corporales impresas en los medios gráficos, en Nexos (Universidad Nacional de Mar del Plata), № 26, año 16, pp. 22-29.

Leopardi, G.; Benjamin, W.; et alt. (2011). Moda - El poder de las apariencias, Revista de Occidente, No 366.

Lipovetsky, G. (1990). El imperio de lo efimero. Barcelona: Anagrama.

(1986). La era del vacío. Barcelona: Anagrama.

Lopez, C. A. (2012), Moda, Diseño, Técnica y Arte reunidos en el concepto del buen vestir. La esencia del oficio y el lenguaje de las formas estéticas del arte sartrial y su aporte a la cultura y el consumo del diseño, en Cuaderno $\mathrm{N}^{\circ} 42$. Buenos Aires: Centro de Estudios en Diseño y Comunicación, Facultad de Diseño y Comunicación de la Universidad de Palermo, pp. 81-99. Lotman, Y. (1999). Cultura y explosión. Barcelona: Gedisa.

Lurie. A. (1994). El lenguaje de la moda. Una interpretación de las formas de vestir. Barcelona: Paidós.

Martinez Barreiro, A. (1996). Elementos para una teoría social de la moda, en Sociológica. Revista de pensamiento social, Universidade da Coruña, 1, pp. 97-123.

Quintas Froufe, N. y Quintas Froufe, E. (2010) La dimensión comunicativa de la moda: el caso español en Zer, vol. 15, Número 28, pp. 197-212.

Schiffer, D. S. (2009). Filosofía del Dandismo. Buenos Aires: Nueva Visión.

Simmel, G. (1938). Cultura Femenina. Buenos Aires: Espasa-Calpe Argentina.

Stefanini Zavallo, V. (2012). El uso del cuerpo en las revistas de moda en Cuadernos del Centro de Estudios en Diseño y Comunicación [Ensayos] No 42. Buenos Aires: Facultad de Diseño y Comunicación, Universidad de Palermo, pp. 193-203.

Veblen, T. (1944). Teoría de la clase ociosa. México: Fondo de Cultura Económica.

Vidal Claramonte, M. C. A. (2003). La magia de lo efímero: representaciones de la mujer en el arte y literatura actuales. Castelló de la Plana: Publicacions de la Universitat Jaume I.

\begin{abstract}
La moda si fa arte quando diventa espressione di una densità estetica che talvolta la ispira e la attraversa. Tuttavia, l'arte di oggi non si limita ad influenzare in maniera considerevole la moda, ma molto spesso si fonde con questa in una disperata ricerca di nuove scene di seduzione e di vendita. In tal senso la moda e il museo sembrano avere dinamiche concordanti. Per altro verso va considerato che lo sviluppo e la diffusione dell'industria culturale hanno condizionato il rapporto tra arte e moda, mettendo così in discussione il concetto stesso di bellezza in quanto categoria fondamentale di tale rapporto.
\end{abstract}

Parole chiave: arte - moda - bellezza - codice - museo - seduzione - stetica.

Summary: Fashion meets art as an expression of aesthetic density that often inspires and crosses. However, today's art is not only a substantial influence for fashion but often merges with that in a desperate search for new scenes of seduction and selling. In this sense, fashion and museum seem to have consistent dynamics. Moreover, the development of cultural industries 
determines the forms of relationship between art and fashion, and questions the beauty as the fundamental category for the meeting.

Keywords: aesthetics - arts - beauty - code - fashion - museum - seduction.

Resumo: A moda se encontra com a arte como expressão de uma densidade estética que muitas vezes a inspira e atravessa. Sem embargo, a arte de hoje não só é uma influência substantiva para a moda senão que, muitas vezes, se fusiona com aquela numa desesperada procura de novos cenários de sedução e de venda. Neste sentido, moda e museu parecem ter dinâmicas concordantes. Por outro lado, a evolução das indústrias culturais condiciona os modos de relação entre arte e moda, e questiona à beleza como a categoria fundamental para o encontro.

Palavras chave: arte - beleza - código - estética - moda - museu - sedução. 